\title{
Aberdeen Meeting of the British Association
}

$I^{\mathrm{N}}$ Iprevious articles reference was made to the suitability of Aberdeen as a centre for excursions and to the arrangements the Local General Committee have made whereby practical effect has been given to this feature of the forthcoming meeting of the British Association there. In the present article it is proposed to outline in brief some of the other local arrangements made for the convenience and enjoyment of visiting members.

The Committee has prepared for issue to members a Local Handbook, containing (1) information as to local arrangements, (2) descriptive articles on the general excursions, and (3) a guide to the City of Aberdeen and environs. These descriptive articles, written by such well-known Scottish authors as J. J. Bell, Evan M. Barron, H. B. Mackintosh and W. Douglas Simpson, should enhance the pleasure derived from participating in the general excursions. In addition, the Committee is issuing a map of the region, a plan of the City and a brochure on the works, etc., which may be visited.

Aberdeen is a city of many industrial interests, and although known as the "Granite City", its chief industry is not concerned with granite. The works to be visited have been chosen with care so as to ensure that a representative panorama of industrial Aberdeen is available for inspection. They include paper mills, a tweed mill, a granite yard, fish works, a fish meal factory, engineering works, a dairy plant, a paint and colour works and an envelope factory.

A feature of special interest has been provided through the courtesy of the Fishery Board for Scotland. The research vessel Explorer belonging to that Department will be berthed in Aberdeen Harbour during the week of the meeting and may be visited by members of the Association. Officials of the department will be aboard and will explain the nature of the work carried out. Weather permitting, a practical demonstration at sea will be given.

As one would expect, the municipal institutions of Aberdeen are operated in a manner which demonstrates at the same time both efficiency and economy in working. Visits to representative departments of municipal activity have been arranged.

Another item of interest is the display of practically all the exhibits shown at the recent Telford Centenary Exhibition in the Institution of Civil Engineers in London. This has been arranged through the courtesy of the owners of these exhibits and the good offices of Sir Alexander Gibb. While an adjunct of Section G (Engineering), the exhibition will be open to all visiting members and a curator will be in attendance to give information relative to the numerous exhibits.

The entertainments include a reception by the Lord Provost, Magistrates and Town Council on the Thursday evening, and in this connexion the civic authorities are arranging a welcome in accord with the traditional hospitality of the City.

On the afternoon of Tuesday, the University of Aberdeen is holding a garden party in the grounds of King's College in Old Aberdeen-a section of the City apart and still retaining in essence the main features of a medieval university town.

During the week commencing Monday, September 10, the students of the University are producing a play entitled "Town and Gown" in His Majesty's Theatre, and Monday and Tuesday performances will be 'British Association performances'. A brochure on the play is being prepared and will be circulated to visiting members; the play is a cavalcade- of great beauty in parts and uproarious fun in other parts. A "British Association" dance has also been arranged to take place in the Beach Ballroom on Tuesday evening. The Beach Ballroom is a beautiful building on the sea front with a dance floor reputed to be the best in Scotland. Various social and golf clubs in the City will be open to visiting members during the week of the meeting. These include the well-known Royal Aberdeen Golf Club at Balgownie - a seaside course among the best in Scotland.

A wide variety of sectional excursions has been arranged, but it is thought scarcely appropriate to refer to these in this article. Full information may be had in the Local Handbook and the Programme and Daily Time Table.

As to accommodation, practically all hotels in Aberdeen have already been booked up, particularly single bedrooms, but there is an ample supply of good class lodgings at reasonable rates. A large number of persons who do not usually let rooms have indicated their willingness to accommodate members of the Association for the week of the meeting.

Apart from these outward indications of the willingness of all interested in the City to ensure to members a happy and profitable visit of the Association to Aberdeen, it should be emphasised that there also awaits members a personal welcome of great cordiality and warmth. The cultural aspect of the Association's activities and the catholicity of interests represented by the thirteen sections make a special appeal to the Aberdonian. The welcome to the Association may be well summed up in the City's famous toast - "Happy to meet, sorry to part, happy to meet again."

\section{The Waite Agricultural Research Institute}

\begin{abstract}
$\mathrm{A}^{\mathrm{N}}$ account of the history and development of the Waite Agricultural Research Institute from the year 1925, when its activities first started, up to 1932 has been issued by the University of Adelaide. Although the chief objective of the Institute is to conduct research on plant and soil problems, it also provides an advisory service to the Department of Agriculture in plant pathology and entomology and gives specialised courses of instruction for the agricultural degrees in the University of Adelaide.
\end{abstract}

The scope of the scientific work undertaken at the Institute covers a wide field. As might be expected, the limited rainfall and the development of a system of cereal and grassland management to suit such conditions, forms one of the major problems, and a study of the water requirements of plants under various manurial treatments and the differences exhibited by improved varieties of cereals and leguminous plants in this respect, has led both to increases in yield being obtained and also to the 